\title{
An association analysis of the HLA gene region in latent autoimmune diabetes in adults
}

\author{
M. Desai • E. Zeggini • V. A. Horton • K. R. Owen • \\ A. T. Hattersley • J. C. Levy • M. Walker • \\ K. M. Gillespie • P. J. Bingley • G. A. Hitman • \\ R. R. Holman • M. I. McCarthy • A. Clark
}

Received: 11 July 2006 / Accepted: 19 September 2006 / Published online: 2 December 2006

(C) Springer-Verlag 2006

\begin{abstract}
Aims/hypothesis Pathophysiological similarities between latent autoimmune diabetes in adults (LADA) and type 1 diabetes indicate an overlap in genetic susceptibility. $H L A$ $D R B 1$ and $H L A-D Q B 1$ are major susceptibility genes for type 1 diabetes but studies of these genes in LADA have been limited. Our aim was to define patterns of $H L A$ encoded susceptibility/protection in a large, well characterised LADA cohort, and to establish association with disease and age at diagnosis.

Materials and methods Patients with LADA $(n=387$, including 211 patients from the UK Prospective Diabetes Study) and non-diabetic control subjects $(n=327)$ were of British/Irish European origin. The HLA-DRB1 and $-D Q B 1$ genes were genotyped by sequence-specific PCR. Results As in type 1 diabetes mellitus, $D R B 1^{*} 0301 \_D Q B 1$
\end{abstract}

Electronic supplementary material Supplementary material is available in the online version of this article at http://dx.doi.org/ $10.1007 / \mathrm{s} 00125-006-0480-4$ and is accessible to authorised users.

M. Desai • E. Zeggini • V. A. Horton · K. R. Owen · J. C. Levy • M. I. McCarthy · A. Clark $(\bowtie)$

Diabetes Research Laboratories, Oxford Centre for Diabetes,

Endocrinology and Metabolism, Churchill Hospital,

University of Oxford,

Headington,

Oxford OX3 7LJ, UK

e-mail: anne.clark@drl.ox.ac.uk

E. Zeggini $\cdot$ M. I. McCarthy

Wellcome Trust Centre for Human Genetics,

University of Oxford,

Oxford, UK

\section{A. T. Hattersley}

Institute of Biomedical and Clinical Sciences,

Peninsula Medical School,

Exeter, UK
*0201 (odds ratio $[\mathrm{OR}]=3.08,95 \%$ CI 2.32-4.12, $p=1.2 \times$ $\left.10^{-16}\right)$ and $D R B 1 * 0401 D Q B 1 * 0302(\mathrm{OR}=2.57,95 \% \mathrm{CI}$ $\left.1.80-3.73, p=4.5 \times 10^{-\overline{8}}\right)$ were the main susceptibility haplotypes in LADA, and $D R B 1 * 1501 \_D Q B 1 * 0602$ was protective $\left(\mathrm{OR}=0.21,95 \%\right.$ CI $\left.0.13-0 . \overline{34}, p=4.2 \times 10^{-13}\right)$. Differential susceptibility was conferred by DR4 subtypes: $D R B 1 * 0401$ was predisposing $(\mathrm{OR}=1.79,95 \%$ CI $1.35-$ 2.38, $p=2.7 \times 10^{-5}$ ) whereas $D R B 1 * 0403$ was protective $(\mathrm{OR}=0.37,95 \%$ CI $0.13-0.97, p=0.033)$. The highest-risk genotypes were $D R B 1 * 0301 / D R B 1 * 0401$ and $D Q B 1 * 0201 /$ $D Q B 1 * 0302\left(\mathrm{OR}=5.14,95 \%\right.$ CI 2.68-10.69, $p=1.3 \times 10^{-8}$; and $\mathrm{OR}=6.88,95 \%$ CI 3.54-14.68, $p=1.2 \times 10^{-11}$, respectively). These genotypes and those containing $D R B 1 * 0401$ and $D Q B 1^{*} 0302$ associated with a younger age at diagnosis in LADA, whereas genotypes containing $D R B 1^{*} 1501$ and $D Q B 1 * 0602$ associated with an older age at diagnosis.

M. Walker

School of Clinical Medical Sciences, University of Newcastle,

Newcastle, UK

R. R. Holman

Diabetes Trials Unit, Oxford Centre for Diabetes,

Endocrinology and Metabolism, University of Oxford,

Oxford, UK

K. M. Gillespie • P. J. Bingley

Diabetes and Metabolism Unit, University of Bristol,

Bristol, UK

G. A. Hitman

Centre for Diabetes and Metabolic Medicine,

Barts and The London,

Queen Mary's School of Medicine and Dentistry,

London, UK 
Conclusions/interpretation Patterns of susceptibility at the $H L A-D R B 1$ and $H L A-D Q B 1$ loci in LADA are similar to those reported for type 1 diabetes, supporting the hypothesis that autoimmune diabetes occurring in adults is an agerelated extension of the pathophysiological process presenting as childhood-onset type 1 diabetes.

Keywords Age of diagnosis · Genetic susceptibility · Protection - Type 1 diabetes

$\begin{array}{ll}\text { Abbreviations } \\ \text { DIF } & \text { Diabetes in Families study } \\ \text { HLA } & \text { human leucocyte antigen } \\ \text { OR } & \text { odds ratio } \\ \text { UKPDS } & \text { UK Prospective Diabetes Study } \\ \text { W2 } & \text { Warren 2 Repository } \\ \text { YT2D } & \text { Exeter Young-Onset Type 2 Diabetes Study }\end{array}$

\section{Introduction}

Latent autoimmune diabetes in adults (LADA) and type 1 diabetes mellitus result from islet beta cell autoimmune destruction and are characterised by the presence of circulating islet autoantibodies. However, the later age of onset and the relatively less acute clinical onset of LADA can result in a clinical diagnosis of type 2 diabetes [1]. Differences in genetic susceptibility could contribute to the variation in both age and clinical severity at onset of autoimmune diabetes.

The HLA gene region is the major susceptibility locus in type 1 diabetes, accounting for $42 \%$ of the total familial risk; primary susceptibility is conferred by the $H L A-D R B 1$ and $H L A-D Q B 1$ genes, and the highest risk is from $D R B 1 * 04-D Q B 1 * 0302$ and $D R B 1 * 0301-D Q B 1 * 0201$ haplotypes, present in $\sim 90 \%$ of type 1 diabetic patients [2]. In type 1 diabetes, the $D R B 1^{*} 0301$ and $D R B 1^{*} 0401$ alleles exhibit positive synergism such that the $D R B 1^{*} 0401 /$ $D R B 1 * 0301$ genotype confers greater risk than either of the two alleles alone [3]. In addition, $D R B 1^{* 0301 /}$ $D R B 1 * 0401$ and $D Q B 1 * 0201 / D Q B 1 * 0302$ genotypes occur more frequently in type 1 diabetic patients diagnosed at earlier ages [4]. Heterogeneity in disease risk conferred by the $D R B 1^{*} 04-D Q B 1^{*} 0302$ haplotype depends upon the allelic subtype of the DR4 antigen specificity present on it: $D R B 1 * 0401, * 0402$ and *0405 associate with increased susceptibility, whereas *0403,*0406 and *0407 confer protection [5]. The $D R B 1 * 1501-D Q B 1 * 0602$ haplotype, which is negatively correlated with age at diagnosis, is considered to be protective against type 1 diabetes [6].

Although the $H L A-D R B 1$ and $H L A-D Q B 1$ genes are good candidate loci for LADA, HLA association studies in
LADA have been hampered by small sample sizes and low genotyping resolution. Predisposing effects of $D R B 1 * 0301$ and $D R B 1 * 0401$ have been demonstrated, but results have been inconsistent [7-9] and a protective effect of $D Q B 1 * 0602$ has not been confirmed throughout [8, 10]. The largest study, using UK Prospective Diabetes Study subjects (UKPDS), employed low-resolution typing restricted to detection of $H L A-D R B 1$ susceptibility variants DRB $1 * 03$ and DRB1*04 [7]. This demonstrated an increased frequency of the $D R B 1 * 03 / D R B 1 * 04$ heterozygote in LADA [7]. However, protective variants were not examined and $H L A-D Q B 1$ allele analysis was restricted to determination of aspartate-57, a putative susceptibility determinant for type 1 diabetes [7].

This investigation extends the previous study [7] by using higher resolution typing and a larger LADA cohort. The aims were to (1) establish association patterns of HLA with disease and compare these with previously reported observations made in type 1 diabetes and (2) determine the relationship of $H L A-D R B 1$ and $H L A-D Q B 1$ genotypes with age at diagnosis.

\section{Subjects and methods}

Subjects LADA subjects $(n=378)$ were from the UKPDS $(n=211)$, the Warren 2 Repository (W2, $n=130)$ [11] and the Exeter Young-Onset Type 2 Diabetes Study (YT2D, $n=$ 37) [12]. They were initially diagnosed with type 2 diabetes and were antibody-positive (for GAD and/or islet antigen 2A, IA-2A), with no requirement for insulin within 3 months after diagnosis. The control population comprised normoglycaemic, GADA/IA-2A-negative spouses/friends of probands recruited as part of the Diabetes in Families study (DIF, $n=327)$. All subjects were unrelated and of British/Irish European origin (Table 1). Informed consent was obtained from all subjects, and all studies were carried out in accordance with the principles of the Declaration of Helsinki (1975, 1983, 2000).

Genotyping The HLA-DRB1 and $H L A-D Q B 1$ genes were genotyped using sequence-specific PCR (PCR-SSP) [13]. Samples with inferred haplotypes that were uncommon or did not conform to known linkage disequilibrium patterns in UK Europids were regenotyped $(n=27)$. Duplicate sample $(n=15)$ genotyping concordance was $100 \%$ for both loci and success was $>95 \%$.

Statistical methods Homogeneity (between LADA groups) and case-control association testing was performed using standard contingency table methods in StatXact 6 (Cytel Software, Cambridge, MA, USA). As appropriate, exact $p$ values were calculated. Haplotype frequencies were esti- 
Table 1 Clinical characteristics of study subjects

\begin{tabular}{|c|c|c|c|c|c|c|}
\hline $\begin{array}{l}\text { Sample } \\
(n)\end{array}$ & $\begin{array}{l}\text { Study } \\
(n)\end{array}$ & $\begin{array}{l}\text { Ascertainment } \\
\text { criteria }\end{array}$ & $\begin{array}{l}\text { Age at onset (years), } \\
\text { mean } \pm \mathrm{SD} \text { (range) }\end{array}$ & $\begin{array}{l}\text { Duration of diabetes } \\
\text { (years), mean } \pm \mathrm{SD}\end{array}$ & $\begin{array}{l}\text { BMI }\left(\mathrm{kg} / \mathrm{m}^{2}\right), \\
\text { mean } \pm \mathrm{SD}\end{array}$ & $\begin{array}{l}\text { Male } \\
(\%)\end{array}$ \\
\hline \multirow[t]{3}{*}{$\begin{array}{l}\text { LADA } \\
(378)\end{array}$} & $\begin{array}{l}\text { UKPDS } \\
(211)\end{array}$ & $\begin{array}{l}\text { Newly diagnosed type } 2 \text { diabetes: not } \\
\text { insulin-requiring within } 3 \text { months of } \\
\text { diagnosis. Ketonuria }<3 \mathrm{mmol} / 1\end{array}$ & $46.3 \pm 10.6(25-65)$ & Studied at diagnosis & $25.1 \pm 4.8^{\mathrm{a}}$ & 52 \\
\hline & $\begin{array}{l}\text { W2 } \\
(130)\end{array}$ & $\begin{array}{l}\text { Clinical diagnosis of type } 2 \text { diabetes: not } \\
\text { insulin requiring within } 12 \text { months of } \\
\text { diagnosis }\end{array}$ & $47.4 \pm 10.0(26-68)$ & $8.9 \pm 6.7^{b}$ & $28.6 \pm 5.3^{\mathrm{b}}$ & 57 \\
\hline & $\begin{array}{l}\text { YT2D } \\
(37)\end{array}$ & $\begin{array}{l}\text { Clinical diagnosis of type } 2 \text { diabetes: not } \\
\text { insulin-requiring within } 3 \text { months of } \\
\text { diagnosis }\end{array}$ & $38.4 \pm 5.4(29-45)$ & $11.9 \pm 7.7^{\mathrm{b}}$ & $27.5 \pm 5.8^{\mathrm{b}}$ & 43 \\
\hline $\begin{array}{l}\text { Control } \\
\text { subjects }\end{array}$ & $\begin{array}{l}\text { DIF } \\
(327)\end{array}$ & $\begin{array}{l}\text { Spouses/friends of probands collected in } \\
\text { the DIF study. Normoglycaemic }\end{array}$ & $55.3 \pm 19.8^{\mathrm{b}}(20-91)$ & N/A & $25.4 \pm 4.0^{\mathrm{b}}$ & 46 \\
\hline
\end{tabular}

Antibody positivity was defined as a titre $>97.5$ th percentile compared with control samples (UKPDS, YT2D and DIF samples measured in the laboratory of P. J. Bingley, University of Bristol) or $>10 \mathrm{U}$ (corresponding to $\sim 8 \mathrm{SD}$ above the mean of 88 normal control subjects) for the W2 samples measured in the laboratory of G. F. Bottazzo (Royal London Hospital). All LADA patients were GADA-positive with the exception of two YT2D patients who were positive for IA-2A only. Control subjects were negative for GADA and IA-2A at sample collection.

${ }^{\text {a }}$ At diagnosis

${ }^{\mathrm{b}}$ At time of sample collection

mated using the expectation maximization algorithm implemented in HelixTree (Golden Helix, Bozeman, MT, USA). For diplotype analyses, the most probable haplotype pair was assigned to each individual and $>97.8 \%$ of assigned haplotypes had posterior probabilities $>0.999$. Distributions of allele, genotype, haplotype and diplotype frequencies between cases and controls were assessed by $2 \times n$ contingency tables (pooling categories with frequencies $<1 \%$ ). Where global tests of association indicated significant differences, variants with frequency $>5 \%$ were tested for disease association by $2 \times 2$ contingency table analysis. Association of age at diagnosis with genotype was initially explored using recursive partitioning, as implemented in HelixTree. Linear regression modelling (SPSS, version 13.0; SPSS, Chicago, IL, USA) was subsequently performed for genotypes containing alleles associated with type 1 diabetes and/or shown to be associated with age at diagnosis. Power calculations (Quanto, version 1.0; http://hydra.usc.edu/ gxe, last accessed in September 2006) indicated that our sample size provided $>80 \%$ power to detect an odds ratio $(\mathrm{OR})>1.85$ for a minor allele frequency of $5 \%$ under the additive model. No corrections for multiple testing were applied and a $p$ value of $<0.05$ was deemed significant.

\section{Results}

Allele frequency distributions between the UKPDS, W2 and YT2D LADA groups did not significantly differ at
$H L A-D R B 1$ and HLA-DQB1 ( $p=0.20$ and 0.81 , respectively). Accordingly, genotyping data of the three patient groups were combined, forming a single group ('LADA'), and compared with control subjects.

The overall distribution of allele frequencies at $H L A$ $D R B 1$ and $H L A-D Q B 1$ differed significantly between LADA and control subjects (both $p<0.0001$ ). Analysis of individual alleles showed predisposing effects of $D R B 1 * 0301(\mathrm{OR}=3.08,95 \%$ CI $2.32-4.11), D R B 1 * 0401$ $(\mathrm{OR}=1.79,95 \%$ CI $1.35-2.38), D Q B 1 * 0201 \quad(\mathrm{OR}=3.19$, $95 \%$ CI $2.40-4.26)$ and $D Q B 1 * 0302(\mathrm{OR}=2.38,95 \%$ CI 1.77-3.25) (Table 2). Protection was conferred by $D R B 1^{* 0403(06 / 07)}(\mathrm{OR}=0.37,95 \%$ CI $0.13-0.97)$, $D R B 1 * 1101(04) \quad(\mathrm{OR}=0.25,95 \%$ CI $0.12-0.48)$, $D R B 1 * 1501-06 \quad(\mathrm{OR}=0.20,95 \%$ CI $0.13-0.32)$, $D Q B 1 * 0301 \quad(\mathrm{OR}=0.51,95 \%$ CI $0.37-0.69), D Q B 1 * 0303$ $(\mathrm{OR}=0.29,95 \%$ CI $0.14-0.57)$ and $D Q B 1^{*} 0602(\mathrm{OR}=0.21$, 95\% CI 0.13-0.34) (Table 2).

The distribution of HLA-DRB1 and HLA-DQB1 genotypes differed significantly between LADA and control subjects $(p<0.0001$; see Electronic supplementary material [ESM] Tables 1 and 2, respectively). Specifically, increased susceptibility to LADA was conferred by genotypes, $D R B 1 * 0301 / D R B 1 * 0401 \quad(\mathrm{OR}=5.14,95 \%$ CI $2.68-$ 10.69), $D R B 1 * 0301 / D R B 1 * 0301 \quad(\mathrm{OR}=4.51,95 \%$ CI 1.93-12.23), $D R B 1 * 0301 / D R B 1 * 0701 \quad(\mathrm{OR}=2.38,95 \%$ CI $1.13-5.38), D Q B 1^{*} 0201 / D Q B 1 * 0302(\mathrm{OR}=6.88,95 \%$ CI 3.54-14.68), $D Q B 1 * 0201 / D Q B 1 * 0201 \quad(\mathrm{OR}=5.11$, 95\% CI 2.21-13.77), $D Q B 1 * 0201 / D Q B 1 * 0202$ (OR= 2.47, 95\% CI 1.04-6.51), DQB1*0201/DQB1*0501 (OR= 
Table $2 H L A-D R B 1$ and $H L A$ $D Q B 1$ allele frequencies and associated OR and $p$ values
All OR were calculated under the multiplicative model and are presented as LADA vs control subjects. Genotyping was checked by two independent researchers.

$N D$ denotes an association not determined because frequencies were $<5 \%$ in both LADA and control groups.

${ }^{\mathrm{a}}$ Data are given as number of chromosomes (frequency).

${ }^{\mathrm{b}}$ LADA $n=754$ for $D Q B 1$ allele.

\begin{tabular}{|c|c|c|c|c|}
\hline & LADA $(n=756)^{\mathrm{a}, \mathrm{b}}$ & Control subjects $(n=654)^{\mathrm{a}}$ & OR $(95 \% \mathrm{CI})$ & $p$ value \\
\hline \multicolumn{5}{|l|}{$D R B 1$ allele } \\
\hline$* 0101$ & $53(0.070)$ & $64(0.098)$ & $0.70(0.47-1.03)$ & 0.066 \\
\hline *0103 & $4(0.005)$ & $3(0.005)$ & & ND \\
\hline$* 0301$ & $236(0.312)$ & $84(0.128)$ & $3.08(2.32-4.11)$ & $9.1 \times 10^{-17}$ \\
\hline$* 0302$ & 0 & $1(0.002)$ & & ND \\
\hline$* 0401$ & $178(0.235)$ & $96(0.147)$ & $1.79(1.35-2.38)$ & $2.7 \times 10^{-5}$ \\
\hline$* 0402$ & $4(0.005)$ & $2(0.003)$ & & ND \\
\hline$* 0403(06 / 07)$ & $7(0.009)$ & $16(0.024)$ & $0.37(0.13-0.97)$ & 0.033 \\
\hline$* 0404$ & $34(0.045)$ & $22(0.034)$ & & ND \\
\hline$* 0405$ & $8(0.011)$ & $3(0.005)$ & & ND \\
\hline$* 0701$ & $100(0.132)$ & $94(0.144)$ & $0.91(0.66-1.25)$ & 0.54 \\
\hline$* 0801$ & $16(0.021)$ & $22(0.034)$ & & ND \\
\hline$* 0901(02)$ & $6(0.008)$ & $9(0.014)$ & & ND \\
\hline$* 1001$ & $1(0.001)$ & $1(0.002)$ & & ND \\
\hline$* 1101(04)$ & $13(0.017)$ & $43(0.066)$ & $0.25(0.12-0.48)$ & $3.4 \times 10^{-6}$ \\
\hline$* 1102(03)$ & $15(0.020)$ & $7(0.011)$ & & ND \\
\hline$* 1201$ & $3(0.004)$ & $10(0.015)$ & & ND \\
\hline$* 1301$ & $20(0.026)$ & $27(0.041)$ & & ND \\
\hline *1302 & $22(0.029)$ & $30(0.046)$ & & ND \\
\hline$* 1303$ & $1(0.001)$ & $1(0.002)$ & & ND \\
\hline$* 1401$ & $5(0.007)$ & $12(0.018)$ & & ND \\
\hline *1501-06 & $26(0.034)$ & $97(0.148)$ & $0.20(0.13-0.32)$ & $2.1 \times 10^{-14}$ \\
\hline$* 1601$ & $4(0.005)$ & $10(0.015)$ & & ND \\
\hline \multicolumn{5}{|l|}{$D Q B 1$ allele } \\
\hline$* 0201$ & $239(0.317)$ & $83(0.127)$ & $3.19(2.40-4.26)$ & $7.1 \times 10^{-18}$ \\
\hline$* 0202$ & $82(0.109)$ & $66(0.101)$ & $1.09(0.76-1.56)$ & 0.66 \\
\hline$* 0301$ & $82(0.109)$ & $127(0.194)$ & $0.51(0.37-0.69)$ & $8.3 \times 10^{-6}$ \\
\hline *0302 & $178(0.236)$ & $75(0.115)$ & $2.38(1.77-3.25)$ & $2.5 \times 10^{-9}$ \\
\hline$* 0303$ & $13(0.017)$ & $37(0.057)$ & $0.29(0.14-0.57)$ & $7.2 \times 10^{-5}$ \\
\hline$* 0401$ & $1(0.001)$ & 0 & & ND \\
\hline$* 0402$ & $16(0.021)$ & $21(0.032)$ & & ND \\
\hline$* 0501$ & $59(0.078)$ & $68(0.104)$ & $0.73(0.50-1.07)$ & 0.094 \\
\hline$* 0502$ & $3(0.004)$ & $10(0.015)$ & & ND \\
\hline$* 0503$ & $4(0.005)$ & $12(0.018)$ & & ND \\
\hline$* 0504$ & $1(0.001)$ & 0 & & ND \\
\hline$* 0601$ & 0 & $4(0.006)$ & & ND \\
\hline$* 0602$ & $25(0.033)$ & $91(0.139)$ & $0.21(0.13-0.34)$ & $2.5 \times 10^{-13}$ \\
\hline$* 0603$ & $15(0.020)$ & $30(0.046)$ & & ND \\
\hline$* 0604$ & $36(0.048)$ & $30(0.046)$ & & ND \\
\hline
\end{tabular}

2.84, 95\% CI 1.07-8.79) and $D Q B 1 * 0302 / D Q B 1 * 0302$ $(\mathrm{OR}=2.84$, 95\% CI 1.07-8.79) (Table 3). Additionally, protective effects of $D R B 1 * 0701 / D R B 1 * 1501-06(\mathrm{OR}=0.05$, $95 \%$ CI $0.001-0.31)$ and $D Q B 1 * 0301 / D Q B 1 * 0602$ $(\mathrm{OR}=0.11,95 \%$ CI $0.02-0.38)$ were observed (Table 3). The highest point estimate for genotypic risk at $H L A$ $D R B 1$ was seen in the $D R B 1^{*} 0301 / D R B 1 * 0401$ heterozygotes, though this was not significantly greater than the estimate for either homozygote group (data not shown).

$D R B 1 \_D Q B 1$ haplotype distribution was different between LADA and control subjects ( $p<0.0001$; ESM Table 3$)$. Haplotypes $D R B 1 * 0301 \_D Q B 1 * 0201$ and $D R B 1 * 0401 \_D Q B 1 * 0302$ were predisposing $(\mathrm{OR}=3.08$,
95\% CI 2.32-4.12; and $\mathrm{OR}=2.57,95 \%$ CI 1.80-3.73, respectively) whereas $D R B 1 * 1101(04) \_D Q B 1 * 0301$ and $D R B 1 * 1501-06 \_D Q B 1 * 0602(\mathrm{OR}=0.25,95 \%$ CI 0.12-0.48; and $\mathrm{OR}=0.21,95 \% \mathrm{CI} 0.13-0.34$, respectively) conferred protection against LADA (Table 4).

Similarly, $D R B 1 \_D Q B 1$ diplotype frequencies differed significantly between LADA and control subjects $(p<$ 0.0001; ESM Table 4), with $D R B 1 * 0301 \_D Q B 1 * 0201$ $D R B 1 * 0401 \_D Q B 1 * 0302$ and $D R B 1 * 0301 \_D Q B 1 * 0201$ $D R B 1 * 0301 \_D Q B 1 * 0201$ occurring more frequently in LADA compared with control subjects $(\mathrm{OR}=8.70,95 \%$ CI 3.67-25.13, $p=8.1 \times 10^{-10}$ and $\mathrm{OR}=4.51,95 \%$ CI $1.93-$ $12.23, p=7.6 \times 10^{-5}$, respectively). A nominally significant 
Table 3 Association of HLA$D R B 1$ and $-D Q B 1$ genotypes (frequencies $>5 \%$ in either cases or controls) with LADA

All OR were calculated as presence of the genotype in question vs all other genotypes and are presented as LADA compared with control subjects.

${ }^{\text {a }}$ Data are given as number of individuals (frequency).

\begin{tabular}{lllll}
\hline & & & & \\
& LADA $^{\mathrm{a}}$ & Control subjects $^{\mathrm{a}}$ & OR $(95 \% \mathrm{CI})$ & $p$ value \\
\hline $\begin{array}{l}\text { DRB1 genotype } \\
* 0301 / 0401\end{array}$ & $62(0.164)$ & $12(0.037)$ & $5.14(2.68-10.69)$ & $1.3 \times 10^{-8}$ \\
$* 0301 * 0301$ & $34(0.090)$ & $7(0.021)$ & $4.51(1.93-12.23)$ & $7.6 \times 10^{-5}$ \\
$* 0301 * 0701$ & $29(0.077)$ & $11(0.034)$ & $2.38(1.13-5.38)$ & 0.014 \\
$* 0401 * 0701$ & $22(0.058)$ & $14(0.043)$ & $1.38(0.66-2.97)$ & 0.39 \\
$* 0701 / 1501-06$ & $1(0.003)$ & $17(0.052)$ & $0.05(0.001-0.31)$ & $2.9 \times 10^{-5}$ \\
$D Q B 1$ genotype & & & & \\
$* 0201 / 0302$ & $73(0.194)$ & $11(0.034)$ & $6.88(3.54-14.68)$ & $1.2 \times 10^{-11}$ \\
$* 0201 * 0201$ & $38(0.101)$ & $7(0.021)$ & $5.11(2.21-13.77)$ & $9.4 \times 10^{-6}$ \\
$* 0201 * 0202$ & $22(0.058)$ & $8(0.024)$ & $2.47(1.04-6.51)$ & 0.038 \\
$* 0201 * 0501$ & $19(0.050)$ & $6(0.018)$ & $2.84(1.07-8.79)$ & 0.024 \\
$* 0302 / * 0302$ & $19(0.050)$ & $6(0.018)$ & $2.84(1.07-8.79)$ & 0.024 \\
$* 0201 * 0301$ & $17(0.045)$ & $17(0.052)$ & $0.86(0.41-1.83)$ & 0.73 \\
$* 0301 * 0602$ & $3(0.008)$ & $22(0.067)$ & $0.11(0.02-0.38)$ & $1.7 \times 10^{-5}$ \\
\hline
\end{tabular}

predisposing effect of $D R B 1 * 0301 \_D Q B 1 * 0201$ $D R B 1 * 0701 \_D Q B 1 * 0202$ was also observed $(\mathrm{OR}=2.46$, 95\% CI 1.04-6.49, $p=0.048$ ).

Diagnostic criteria for LADA have been proposed, including age at diagnosis $>30$ years and no clinical requirement for insulin within 6 months after diagnosis [14]. Using these criteria, we repeated the analyses, excluding 50 non-compliant cases. The effect sizes (odd ratios) were comparable (data not shown) with those described above.

Within the LADA group, the $D R B 1^{*} 0301 / * 0401$ genotype associated with a younger age of diagnosis (mean age \pm $\mathrm{SD}$ in carriers vs non-carriers, $42.1 \pm 10.3$ vs $46.6 \pm$ 10.2 years, $p=0.0016$ ), as did possession of the $D R B 1^{*} 0401$ allele $(43.8 \pm 9.8$ vs $47.4 \pm 10.5$ years, $p=$ $0.00075)$. Similarly, an earlier age of diagnosis was associated with the $D Q B 1 * 0201 / D Q B 1 * 0302$ genotype $(42.8 \pm 9.8$ vs $46.5 \pm 10.3$ years, $p=0.0051)$ and with possession of the $D Q B 1^{*} 0302$ allele $(44.3 \pm 9.8$ vs $46.9 \pm$ 10.5 years, $p=0.018)$. Conversely, patients carrying $D R B 1 * 1501-06$ were older at diagnosis than those not carrying this allele $(50.3 \pm 10.7$ vs $45.6 \pm 10.2$ years, $p=$ $0.030)$, as were carriers of $D Q B 1^{*} 0602(50.3 \pm 10.7$ vs $45.5 \pm 10.2$ years, $p=0.029$ ).

\section{Discussion}

The major LADA susceptibility determinants at the two loci were $D R B 1 * 0301, D R B 1 * 0401, D Q B 1 * 0201$ and $D Q B 1 * 0302$. This confirms previously reported genotype associations of $D R B 1 * 0301 / D R B 1 * 0401, D R B 1 * 0301 /$ $D R B 1 * 0301, D Q B 1 * 0201 / D Q B 1 * 0201, D Q B 1 * 0201 /$ $D Q B 1 * 0302$ and $D Q B 1 * 0302 / D Q B 1 * 0302$ in LADA [7, 8]. This is the first report to demonstrate that DR4 antigen specificity subtypes confer differential risk of LADA: $D R B 1 * 0401$ conferred susceptibility to LADA, whereas $D R B 1^{*} 0403(06 / 07)$ had a protective effect. The synergistic effects of the $D R B 1^{*} 0301$ and $D R B 1^{*} 0401$ alleles reported in type 1 diabetes [3] were not statistically significant in LADA, although the greatest point estimate for genotypic risk at $H L A-D R B 1$ was observed for DRB1*0301/ $D R B 1^{*} 0401$ heterozygotes, which conferred an approximately 5 -fold risk of disease $(\mathrm{OR}=5.14,95 \%$ CI 2.68 $10.69, p=1.3 \times 10^{-8}$ ).

The major protective alleles in our LADA cohort were $D R B 1 * 1501-06$ and $D Q B 1 * 0602$, as seen in Swedish patients [10] though not in Finns [8]. DRBI*1101(04), $D Q B 1^{*} 0301$ and $D Q B 1^{*} 0303$ were also protective, as seen in type 1 diabetes [2]. However, we found that
Table 4 Association of HLA$D R B 1 \_D Q B 1$ haplotypes (frequencies $>5 \%$ in either cases or controls) with LADA

All OR are calculated under the multiplicative model and are presented as LADA vs control subjects

${ }^{a}$ Data are given as number of chromosomes (frequency)

\begin{tabular}{lllll}
\hline Haplotype & LADA $^{\mathrm{a}}$ & Control subjects $^{\mathrm{a}}$ & OR $(95 \%$ CI $)$ & $p$ value \\
\hline *0301_*0201 & $234(0.310)$ & $83(0.127)$ & $3.08(2.32-4.12)$ & $1.2 \times 10^{-16}$ \\
$* 0401 * 0302$ & $128(0.169)$ & $48(0.073)$ & $2.57(1.80-3.73)$ & $4.5 \times 10^{-8}$ \\
$* 0701 * 0202$ & $81(0.107)$ & $64(0.098)$ & $1.11(0.77-1.59)$ & 0.60 \\
$* 0101 * 0501$ & $52(0.069)$ & $64(0.098)$ & $0.68(0.46-1.02)$ & 0.052 \\
$* 0401 * 0301$ & $49(0.065)$ & $47(0.072)$ & $0.90(0.58-1.39)$ & 0.60 \\
$* 1501-06 * 0602$ & $25(0.033)$ & $90(0.138)$ & $0.21(0.13-0.34)$ & $4.2 \times 10^{-13}$ \\
$* 1101(04) * 0301$ & $13(0.017)$ & $43(0.066)$ & $0.25(0.12-0.48)$ & $3.4 \times 10^{-6}$ \\
\hline
\end{tabular}


$D R B 1 \_D Q B 1$ haplotypes/diplotypes were very strongly associated with LADA and, in some cases, could account for the genotype/allele effects, e.g. protection conferred by $D R B 1 * 1101(04) \_D Q B 1 * 0301$. The age-related associations observed in this study are similar to those reported in type 1 diabetes and LADA [4, 6, 7].

We conclude that the architecture of HLA-conferred susceptibility to LADA is similar to that observed in type 1 diabetes, although individual effect sizes may differ. Susceptibility conferred by the insulin gene region is indistinguishable from that observed in type 1 diabetes [15]. Thus, similarities in genetic predisposition conferred by the two major type 1 diabetes susceptibility loci suggest that adult-onset autoimmune diabetes is an age-related extension of the pathophysiological process presenting as type 1 diabetes in children.

Acknowledgements We thank J. Ayers and M. Barnardo at the Tissue Typing Laboratories (Churchill Hospital, Oxford, UK) for use of genotyping facilities and their expert advice, and A. Malloy for genotyping assistance. We acknowledge the laboratory of G. F. Bottazzo (Royal London Hospital, UK) for performing antibody testing of study subjects. E. Zeggini is a Wellcome Trust Research Career Development Fellow. This work was funded by Diabetes UK (V. A. Horton, M. Desai) and the Wellcome Trust (A. Clark.).

Duality of interest None of the authors have any conflicts of interest.

\section{References}

1. Tuomi T, Groop LC, Zimmet PZ et al (1993) Antibodies to glutamic acid decarboxylase reveal latent autoimmune diabetes mellitus in adults with a non-insulin-dependent onset of disease. Diabetes 42:359-362

2. Redondo MJ, Fain PR, Eisenbarth GS (2001) Genetics of type 1A diabetes. Recent Prog Horm Res 56:69-89

3. Thomson G (1988) HLA disease associations: models for insulin dependent diabetes mellitus and the study of complex human genetic disorders. Annu Rev Genet 22:31-50
4. Caillat-Zucman S, Garchon HJ, Timsit J et al (1992) Agedependent HLA genetic heterogeneity of type 1 insulin-dependent diabetes mellitus. J Clin Invest 90:2242-2250

5. Rewers A, Babu S, Wang TB et al (2003) Ethnic differences in the associations between the HLA-DRB1*04 subtypes and type 1 diabetes. Ann N Y Acad Sci 1005:301-309

6. Graham J, Kockum I, Sanjeevi CB et al (1999) Negative association between type 1 diabetes and HLA DQB1*0602DQA $1 * 0102$ is attenuated with age at onset. Swedish Childhood Diabetes Study Group. Eur J Immunogenet 26:117-127

7. Horton V, Stratton I, Bottazzo GF et al (1999) Genetic heterogeneity of autoimmune diabetes: age of presentation in adults is influenced by HLA DRB1 and DQB1 genotypes (UKPDS 43). UK Prospective Diabetes Study (UKPDS) Group. Diabetologia 42:608-616

8. Tuomi T, Carlsson A, Li H et al (1999) Clinical and genetic characteristics of type 2 diabetes with and without GAD antibodies. Diabetes 48:150-157

9. Vatay A, Rajczy K, Pozsonyi E et al (2002) Differences in the genetic background of latent autoimmune diabetes in adults (LADA) and type 1 diabetes mellitus. Immunol Lett 84:109-115

10. Stenstrom G, Berger B, Borg H et al (2002) HLA-DQ genotypes in classic type 1 diabetes and in latent autoimmune diabetes of the adult. Am J Epidemiol 156:787-796

11. Wiltshire S, Hattersley AT, Hitman GA et al (2001) A genomewide scan for loci predisposing to type 2 diabetes in a U.K. population (the Diabetes UK Warren 2 Repository): analysis of 573 pedigrees provides independent replication of a susceptibility locus on chromosome 1q. Am J Hum Genet 69:553-569

12. Owen KR, Stride A, Ellard S, Hattersley AT (2003) Etiological investigation of diabetes in young adults presenting with apparent type 2 diabetes. Diabetes Care 26:2088-2093

13. Bunce M, O'Neill CM, Barnardo MC et al (1995) Phototyping: comprehensive DNA typing for HLA-A, B, C, DRB1, DRB3, DRB4, DRB5 \& DQB1 by PCR with 144 primer mixes utilizing sequence-specific primers (PCR-SSP). Tissue Antigens 46:355367

14. Palmer JP, Hampe CS, Chiu H, Goel A, Brooks-Worrell BM (2005) Is latent autoimmune diabetes in adults distinct from type 1 diabetes or just type 1 diabetes at an older age? Diabetes 54:S62 S67

15. Desai M, Zeggini E, Horton VA et al (2006) The variable number of tandem repeats upstream of the insulin gene is a susceptibility locus for latent autoimmune diabetes in adults. Diabetes 55:18901894 